\title{
Pengaruh Penerapan Metode Bermain Peran terhadap Prestasi Belajar pada Mata Pelajaran Sejarah Kebudayaan Islam Siswa Madrasah Tsanawiyah (MTs) Arruhama Kuningan
}

\author{
Dhea Abdul Majid, Iwan, Suteja \\ Fakultas Ilmu Tarbiyah dan Keguruan \\ Institut Agama Islam Negeri Syekh Nurjati Cirebon
}

\begin{abstract}
Abstrak
Penelitian ini memiliki latar belakang masalah terkait prestasi belajar siswa Madrasah Tsanawiyah (MTs) Arruhama Kecamatan Cilimus Kabupaten Kuningan pada mata pelajaran Sejarah Kebudayaan Islam (SKI). Peneliti menemukan masalah, yakni dengan melihat hasil UTS di mana siswa yang mencapai KKM (Kriteria Ketuntasan Minimum) hanya sebesar 60\%, dalam pembelajaran Sejarah Kebudayaan Islam.

Penelitian ini bertujuan untuk mengetahui pengaruh penerapan metode bermain peran terhadap prestasi belajar mata pelajaran Sejarah Kebudayaan Islam siswa MTs Arruhama Kecamatan Cilimus Kabupaten Kuningan, untuk mengetahui pengaruh penerapan metode bermain peran terhadap prestasi belajar siswa di MTs Arruhama Kecamatan Cilimus Kabupaten Kuningan.

Bermain peran sebagai suatu model pembelajaran bertujuan untuk membantu siswa menemukan makna diri (jati diri) di dunia sosial dan memecahkan dilema dengan bantuan kelompok. Artinya, melalui bermain peran siswa belajar mengungkapkan konsep peran, menyadari adanya peran-peran yang berbeda dan memikirkan perilaku dirinya dan perilaku orang lain.

Teknikpengumpulan data yang dilakukandalampenelitianini, antara lain: angket, observasi, wawancaradandokumentasi, sedangkanuntukteknikanalisis data yaitudenganmenggunakanrumuskorelasiproduct moment.

Berdasarkan hasil penelitian, jumlah skor rata-rata jawaban angket tentang pengaruh metode bermain peran pada mata pelajaran Sejarah Kebudayaan Islam rata-rata pencapian sebagian besar berada pada kategori baik dengan rata-rata prosentase pencapaian sebesar 70\%. Sedangkan prestasi belajar mata pelajaranSejarah Kebudayaan Islam rata-rata nilai pencapaian sebesar 52,12 terletak padakategori cukup,dapat disimpulkan bahwa pengaruh penerapan metode bermain peran terhadap prestasi belajar siswa terdapat korelasi yang termasuk kedalam kategori korelasi yang lemah atau rendah sebesar $(0,24)$.
\end{abstract}

Kata Kunci: Metode Bermain Peran, Prestasi Belajar Siswa 


\section{A. Pendahuluan}

\section{Penghantar dan Pembahasan Awal}

Pendidikan Nasional berfungsi mengembangkan kemampuan dan membentuk watak serta peradaban bangsa yang bermartabat dalam rangka mencerdaskan kehidupan bangsa, bertujuan untuk berkembangnya potensi peserta didik agar menjadi manusia yang beriman dan bertakwa kepada Tuhan Yang Maha Esa, berakhlak mulia, sehat, berilmu, cakap dan kreatif, mandiri, dan menjadi warga negara yang baik dan bertanggung jawab. ${ }^{1}$

Pendidikan merupakan masalah yang sangat penting dalam kehidupan bangsa dan negara, maka hampir seluruh negara di dunia ini menangani secara langsung masalah-masalah yang berhubungan dengan pendidikan. Secara umum pengertian pendidikan adalah bimbingan atau pimpinan secara sadar oleh pendidik terhadap perkembangan jasmani dan rohani anak didik menuju terbentuknya kepibadian yang utama. ${ }^{2}$

Proses pendidikan adalah proses penyadaran agar terjadi dialektika terhadap tindakan tertentu dan terhadap obyektifikasi dunia di mana ia berada. Bisa kita lihat bahwasanya kekuasaan itu perlu diikuti oleh kesadaran yang tidak melanggar aturan yang telah ada. ${ }^{3}$

Prestasi peserta didik tentulah merupakan tujuan akhir yang hendak dicapai. Faktor pendukung berhasilnya prestasi yang baik, itu ditopang dalam beberapa komponen yaitu; pendidik, bahan ajar, media, strategi, metode, dan lain-lain. Komponen ini hendaknya saling bersinergi satu sama lainnya, dalam setiap pembelajaran. Dan guru dituntut mampu mahir menguasai seluruh komponen yang ada.

Penentu prestasi belajar yang sangat mendasar adalah metode yang cocok dengan materi pembelajaran. Tidak semua materi bisa menggunakan metode yang sama karena metode merupakan suatu alat yang mempermudah untuk mencapai tujuan pembelajaran. Metode yang baik, akan menghasilkan prestasi yang baik pula. Metode yang kurang baik, akan menghasilkan prestasi yang kurang baik pula. Namun terkadang metode yang sudah baik, tidak mampu mendongkrak prestasi, dan ini merupakan suatu permasalahan.

Berdasarkan hasil pengamatan di lapangan yang ada, ditemukan suatu permasalahan, yaitu tentang prestasi belajar siswa pada mata pelajaran Sejarah Kebudayaan Islam (SKI), di mana banyak siswa yang memiliki potensi, namun faktanya potensi yang ada itu tidak dapat tersalurkan prestasi belajarnya dengan maksimal.

Nilai KKM (Kriteria Ketuntasan Minimum) pada mata pelajaran Sejarah Kebudayaan Islam adalah 75, nilai yang cukup besar bagi peserta didik. Di mana, setiap UTS anak-anak yang mendapatkan nilai di atas KKM itu kirakira hanya $60 \%$ dan sisanya $40 \%$ yang tidak memenuhi syarat ketuntasan (remedial).

\footnotetext{
${ }^{1}$ UUSISDIKNAS, (2003), 7.

${ }^{2}$ Ahmad Tafsir, Ilmu Pendidikan Islam(Bandung: PT Remaja Offset, 2012),36.

${ }^{3}$ H.A.R Tilaar, Pedagogik Teoritis(Jakarta: PT. Kompas Nusantara, 2015), 113.
} 
Dan dari sini penulis melihat bahwa titik permasalahan yang ada ini pada sisi metode, salah satunya metode ceramah yang sudah cukup lama dipakaidalam dunia pendidikan maupun syiar Islam. Namun tidak semua materi bisa menggunakan metode ceramah jika peserta didik menjadi pusat pembelajaran (Student Centre), tetapi metode ceramah bisa diterapkan terhadap pembelajaran orang dewasa (andragogi).

Metode adalah cara untuk menyampaikan materi agar mencapai tujuan yang telah ditetapkan, fungsi metode ini tidak bisa diabaikan begitu saja, karena metode turut mentukan berhasil atau tidaknya suatu proses belajar mengajar. ${ }^{4}$

Metode bermain peran adalah metode pembelajaran yang di dalamnya menampakkan perilaku pura-pura dan menghayati tokoh yang telah diberikan oleh guru. Dan bertujuan untuk melatih keaktifan siswa serta menimbulkan keberanian untuk tampil di depan kelas, dan bertujuan untuk memperkenalkan sejarah dengan cara memainkan tokoh yang ada. ${ }^{5}$

Sebagaimana Allah mengutus Nabi Muhammad SAW untuk dijadikan teladan dengan segala kebaikannya yag ada pada diri Rasul. Sebagaimana dalam surat Al-Ahzab ayat 21, Allah berfirman:

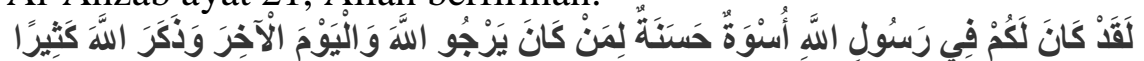

"Sesungguhnya telah ada pada (diri) Rasulullah itu suri teladan yang baik bagimu (yaitu) bagi orang yang mengharap (rahmat) Allah dan (kedatangan) hari kiamat dan dia banyak menyebut Allah." 6

Menurut Tafsir Ibnu Katsir surat Al-Ahzab ayat 21, menerangkan bahwa: Allah SWT berfirman: "Mengapa kamu tidak berteladan kepada Rasulullah , betapa ia menghadapi musuh dan perang Khandaq (Ahzab) dengan penuh kesabaran, ketetapan hati, keberanian dan kepercayaan penuh akan pertolongan Allah yang dijanjikan. Bukanlah Allah telah menjadikan dalam diri Rasul-Nya suri taeladan yang baik bagi para pengikutnya, orang-orang mukmin yang mengharapkan rahmat dan ridha serta yang beriman kepada hari kiamat".

\section{Rumusan Masalah}

Dari kajian di atas, timbul suatu pertanyaan:

a. Apakah Ada Perubahan Dalam Segi Kegiatan Belajar Mengajar (KBM) Setelah Menerapakan Metode Bermain Peran Pada Mata Pelajaran Sejarah Kebudayaan Islam?

b. Apakah Prestasi Belajar Siswa Lebih Meningkat Setelah Menggunakan Metode Bermain Peran?

c. Seberapa Besar Pengaruh Penerapan Metode Bermain Peran Terhadap Prestasi Belajar Mata Pelajaran Sejarah Kebudayaan Islam Siswa MTs Arruhama Kecamatan Cilimus Kabupaten Kuningan?

\footnotetext{
${ }^{4}$ Basyiruddin Usman, Metodologi Pembelajaran Agama Islam(Jakarta: Ciputat Press, 2002), 1.

${ }^{5}$ Mulyono ,Strategi Pembelajaran(Malang: UIN-Maliki Press, 2012), 45.

${ }^{6}$ DEPAG (Departemen Agama), (2012), 595.

${ }^{7}$ Salim Bahreisy dan Said Bahreisy, Terjemah Singkat Tafsir Ibnu Katsir Jilid 6(Surabaya: PT. Bina Ilmu, 2006),304.
} 


\section{Tujuan Penelitian}

Berdasarkan permasalahan di atas, penelitian ini bertujuan untuk:

1. Untuk Mengetahui Adanya Perubahan Kegiatan Belajar Mengajar (KBM) Setelah Menerapkan Metode Bermain Peran Pada Mata Pelajaran Sejarah Kebudayaan Islam (SKI).

2. Untuk Mengetahui Peningkatan Prestasi Belajar Siswa MTs Arruhama Kecamatan Cilimus Kabupaten Kuningan Setelah Menggunakan Metode Bermain Peran.

3. Untuk Mengetahui Seberapa Besar Pengaruh Penerapan Metode Bermain Peran Terhadap Prestasi Belajar Mata Pelajaran Sejarah Kebudayaan Islam Siswa MTs Arruhama Kecamatan Cilimus Kabupaten Kuningan.

\section{Kegunaan Penelitian}

a. Dari segi Praktis, agar penulis dapat memperkaya wawasan bidang kependidikan dan lebih mengetahui secara mendalam dan terperinci, serta dapat dijadikan bahan masukan (Input) dalam rangka memberikan kontribusi mengenai pengaruh penerapan metode bermain peran terhadap prestasi belajar mata pelajaran Sejarah Kebudayaan Islam (SKI) siswa MTs Arruhama Kecamatan Ciimus Kabupaten Kuningan.

b. Dari segi Teoritis, bagi akademis penelitian ini diharapkan memberikan manfaat berupa pengaruh penerapan metode bermain peran terhadap prestasi belajar mata pelajaran Sejarah Kebudayaan Islam (SKI) di MTs Arruhama Kecamtan Cilimus Kabupaten Kuningan.

\section{Langkah-Langkah Penelitian}

a. Sumber Data

1) Sumber Literer (field literature) yaitu sumber data yang digunakan untuk mencari landasan teori tentang permasalahan yang diteliti dengan menggunakan buku-buku perpustakaan.

2) Field Research yaitu sumber data yang diperoleh dari lapangan penelitian, yaitu mencari data dengan cara terjun langsung ke obyek penelitian, untuk memperoleh data yang lebih konkrit yang berkaitan dengan masalah yang diteliti.

b. Menentukan Populasi dan Sampel

1) Populasi

Menurut Arikunto populasi adalah keseluruhan objek penelitian. Dalam penelitian ini yang dijadikan populasi adalah siswa MTs Arruhama. ${ }^{8}$

2) Sampel

Pada penelitian ini penulis mengambil teknik pengambilan data dengan cara Cluster sampling yang dimana mengacu pada kelompok bukan individu. Sampel dalam penelitian ini adalah kelas VII yang berjumlah 33 orang.

${ }^{8}$ Suharsimi Arikunto, Prosedur Penelitian(Jakarta: Rineka Cipta, 1996), 102. 


\section{B. Metode Bermain Peran}

Metode ialah cara yang paling tepat dalam melakukan sesuatu, maka urutan kerja dalam suatu metode harus diperhitungkan secara ilmiah, karena metode adalah hasil eksperimen, maka suatu konsep yang dierksperimenkan haruslah telah melalui uji teori dengan kata lain suatu konsep yang telah diterima secara teoritis yang boleh dieksperimenkan. ${ }^{9}$

Sedangkan menurut Basyiruddin,metode pengajaran yaitu suatu cara penyampaian bahan pelajaran untuk mencapai tujuan yang ditetapkan, maka fungsi metode mengajar tidak dapat diabaikan, karena metode mengajar tersebut turut menentukan berhasil tidaknya suatu proses belajar mengajar dan merupakan bagian integral dalam suatu sistem pengajaran. ${ }^{10}$ Metode ini, pertama dibuat berdasarkan asumsi bahwa sangatlah munkin menciptakan analogi otentik ke dalam situasi permasalahan kehidupan nyata. Kedua, bahwa bermain peran dapat mendorong siswa mengeks-presikan perasaannya. Ketiga, bahwa proses psikologis melibatkan sikap, nilai, dan keyakinan (belief). Sehingga kita mengarahkan pada kesadaran melalui keterlibatan spontan yang disertai analisis. Model yang seperti ini dipelopori oleh George Shaftel. ${ }^{1}$

Menurut Jumanta Hamdayama bermain peran pada prinsipnya merupakan pembelajaran untuk menghadirkan peran-peran yang ada di dalam dunia nyata ke dalam suatu pertunjukan peran di dalam kelas. Pembelajaran yang menggunakan dengan metode bermain peran lebih menekankan pada pertunjukan yang dipentaskan. Metode bermain peran merupakan suatu cara penguasaan bahan-bahan pelajaran melalui pengembangan imajinasi dan penghayatan siswa. Pengembangan imajinasi dan penghayatan dilakukan siswa dengan memerankannya sebagai salah satu tokoh atau benda mati. Pada umumnya dilakukan lebih dari satu orang, hal itu bergantung kepada apa yang akan diperankan. ${ }^{12}$

\section{Prestasi Belajar}

Kata prestasi belajar berasal dari dua suku kata, yaitu "prestasi dan "belajar". Di dalam Kamus Besar Bahasa Indonesia, yang dimaksud dengan prestasi adalah : Hasil yang telah dicapai dari yang telah dilakukan, dikerjakan, dan sebagainya. ${ }^{13} \mathrm{Hal}$ tersebut senada dengan pengertian prestasi belajar dalam Kamus Besar Bahasa Indonesia (KBBI): "penguasaan, pengetahuan atau keterampilan yang dikembangkan oleh mata pelajaran,

\footnotetext{
${ }^{9}$ Ahmad Tafsir,Ilmu Pendidikan Islam....., 9.

${ }^{10}$ Basyiruddin Usman, Metodologi Pembelajaran................., 1.

${ }^{11}$ Hamzah B. Uno, Model Pembelajaran (Menciptakan Proses BelajarMengajar yang Kreatif dan Efektif), Jakarta: PT. Bumi Aksara, 2014), 25.

${ }^{12}$ Jumanta Hamdayama, Model dan Metode Pembelajaran Kreatif dan Berkarakter,(Jakarta: Ghalia Indonesia, 2014), 188-189.

${ }^{13}$ Departemen Pendidikan Nasional, (2008), 101.
} 
lazimnya ditunjukkan dengan nilai tes atau angka nilai yang diberikan oleh guru. ${ }^{14}$

Jadi, hasil belajar atau prestasi belajar adalah sejumlah pengalaman yang diperoleh siswa yang mencakup ranah kognitif, afektif, dan psikomotorik. Belajar tidak hanya penguasaan konsep teori mata pelajaran saja, tapi juga penguasaan kebiasaan, persepsi, kesenangan, minat-bakat, penyesuaian sosial, macam-macam keterampilan, cita-cita, keinginan dan harapan. ${ }^{15}$

\section{Metode Penelitian}

Metode yang digunakan dalam penelitian ini adalah metode kuantitatif. Metode kuantitatif adalah penelitian yang berdasarkan pada filsafat positivisme, digunakan untuk meneliti pada populasi sampel tertentu, teknik pengambilan sampel pada umumnya dilakukan secara random, pengumpulan dan menggunakan instrumen penelitian, dan analisis data bersifat statistik dengan tujuan untuk menguji hipotesis yang telah ditetapkan. ${ }^{16}$

Menurut Arikunto populasi adalah keseluruhan objek penelitian. ${ }^{17}$ Dalam penelitian ini yang dijadikan populasi adalah siswa MTs Arruhama,dengan menggunakan teknik pengambilan data melalui cara Cluster sampling yang dimana mengacu pada kelompok bukan individu. Berkaitan dengan hal ini Suharsimi Arikunto berpendapat, Apabila subjeknya kurang dari 100 lebih baik diambil semua sehingga penelitiannya merupakan penelitian populasi selanjutnya jika jumlah subyeknya besar, maka dapat diambil antara 10-15\%, 20-25\%, atau lebih, sesuai dengan kemampuan peneliti $^{18}$, karena populasi data penelitian ini lebih dari 100, maka peneliti mengambil sampel 15\% saja, dengan demikian jumlah sampel pada skripsi ini adalah $15 \%$ X 199=29,85 dibulatkan menjadi 33 0rang.

\section{E. Teknik Analisis Data}

Analisis data merupakan proses penyederhanaan ke dalam bentuk yang lebih mudah dibaca dan diinterprestasikan. Untuk mengetahui bagaimana pengaruh metode diskusi terhadap prestasi belajar mata pelajaran Sejarah Kebudayaan Islam, maka dalam analisa data ini penulis menggunakan nilai rata-rata sebagai pembatas, sebagaimana yang diutarakan oleh Suharsimi Arikunto (2013:296) yaitu:

1. Nilai yang berada di atas rata-rata menunjukkan kategori "Tinggi" disingkat $\mathrm{T}$.

2. Nilai rata-rata dan lebih rendah dari rata-rata menunjukkan kategori "Rendah", disingkat R.

\footnotetext{
${ }^{14}$ Depdikbud, Kamus Besar Bahasa Indonesia (KBBI), (Jakarta: Balai Pustaka, 1996/2008), 110.

${ }^{15}$ Rusman, Pembelajaran Tematik Terpadu (Teori, Praktik dan Penilaian),(Jakarta: PT. RajaGrafindo Persada, 2015), 67.

${ }^{16}$ Sugiyono, Metode Penelitian Pendidikan(Bandung: Alfabeta, 2011),14.

${ }^{17}$ Suharsimi Arikunto, Prosedur Penelitian(Jakarta: Rineka Cipta, 1996), 102.

${ }^{18}$ Suharsimi Arikunto, Prosedur Penelitian 117.
} 
Adapun dalam menganalisa data tentang pengaruh variabel $\mathrm{X}$ terhadap variabel Y menggunakan rumus korelasi "product moment", yaitu hubungan antara dua variabel sebagai berikut:

$$
r_{x y}=\frac{N \sum X Y-\left(\sum X\right)\left(\sum Y\right)}{\sqrt{\left\{N \sum X^{2}-\left(\sum X\right)^{2}\right\}\left\{N \sum Y^{2}-\left(\sum Y\right)^{2}\right\}}}
$$

Keterangan:

$$
\begin{array}{ll}
r_{x y} & : \text { angka indeks korelasi " } \mathrm{r} \text { " product moment } \\
N & : \text { jumlah responden } \\
\sum \mathrm{XY} & : \text { jumlah hasil perkalianantara skor Xdan } \mathrm{Y} \\
\sum \mathrm{X} & : \text { jumlah seluruh skor } \mathrm{X} \\
\sum \mathrm{Y} & : \text { jumlah seluruh skor } \mathrm{Y}^{19}
\end{array}
$$

Selanjutnya untuk memberikaninterpretasi secara sederhana angka indeks korelasi " $\mathrm{r}$ " product moment $\left(\mathrm{r}_{\mathrm{xy}}\right)$ diperlukan pedoman sebagai berikut $^{20}$ :

\section{Korelasi}

\begin{tabular}{|l|l|}
\hline Interval Koefisien & Tingkat Hubungan \\
\hline $0,00-0,20$ & SangatRendah \\
$0,20-0,40$ & Rendah atau Lemah \\
$0,40-0,70$ & Sedang \\
$0,70-0,90$ & Kuat atau Tinggi \\
\hline
\end{tabular}

Memberikan interpretasi dengan cara berkonsultasi pada table nilai "r" product moment

${ }^{19}$ Anas Sudijono, Pengantar Statistik Pendidikan(Jakarta: PT Raja Grafindo Persada, 2012), 206.

${ }^{20}$ Anas Sudijono,Pengantar Statistik........., 193. 
Agar lebih mudah terprestasi terhadap angka dekskorelasi " $r$ " product moment dapat ditempuh dengan jalan berkonsultasi pada tabel "r" product moment, prodesurnya adalah sebagai berikut:

a) Merumuskan hipotesa alternative (Ha) dan hipotesa nihil (Ho)

b) Koefesien Determinasi

$$
\mathrm{KD}=\left(\mathrm{r}_{\mathrm{xy}}\right)^{2} \times 100 \%
$$

Keterangan:

KD : Koefesien Determinasi

$\mathrm{r}_{\mathrm{xy}} \quad$ : hasil nilai observasi yang dikuadratkan

$100 \%:$ : persentase $^{21}$

Dalam hal ini, nilai $\mathrm{r}_{\mathrm{xy}}$ diartikan sebagai koefesien validasi, sehingga kriterianya menjadi:

$$
\begin{array}{ll}
0,80-1,00 & \text { : korelasi tinggi } \\
0,60-0,80 & : \text { korelasi cukup } \\
0,40-0,60 & : \text { korelasi sedang } \\
0,20-0,40 & : \text { korelasi rendah } \\
0,00-0,20 & : \text { korelasi sangat rendah }
\end{array}
$$

\section{Hipotesis Statistik}

Hipotesis merupakan jawaban yang sifatnya sementara terhadap permasalahan yang diajukan dalam penelitian. Hipotesis belum tentu benar. Benar tidaknya suatu hipotesis tergantung hasil pengujian dari data empiris. ${ }^{23}$

Berdasarkan keterangan di atas, maka dapat dirumuskan hipotesis sebagai berikut:

Ho: Tidak ada hubungan yang signifikan antara pengaruh penerapan metode diskusi terhadap prestasai pada mata pelajaran Sejarah Kebudayaan Islam (SKI).

Ha: Ada hubungan yang signifikan antara pengaruh penerapan metode bermain peran terhadap prestasai pada mata pelajaran Sejarah Kebudayaan Islam (SKI).

\section{Rekapitulasi Hasil Angket Variabel X}

(Metode Bermain Peran)

\begin{tabular}{|c|ll|c|}
\hline No. Item Pernyataan & \multicolumn{1}{|c|}{ Variabel } & Skor Rata-rata $\bar{\chi})$ \\
\hline 1 & a. $\quad$ Selalu & 2 \\
\hline 2 & b. $\quad$ Sering & 2,1 \\
\hline 3 & c. $\quad$ Kadang-kadang & 3,03 \\
\cline { 1 - 1 } & d. & Tidak Pernah & 3,03 \\
\hline 4 & &
\end{tabular}

\footnotetext{
${ }^{21}$ Subana, dkk, Statistik Pendidikan(Bandung: Putra Setia, 2000), 145.

${ }^{22}$ Riduwan, Dasar-dasar Statistika (Bandung: Alfabeta, 2013), 228.

${ }^{23}$ Yatim Riyanto, (2010) hal. 16
} 


\begin{tabular}{|c|c|}
\hline 5 & 3,30 \\
\hline 6 & 2,12 \\
\hline 7 & 2,70 \\
\hline 8 & 2,15 \\
\hline 9 & 3,2 \\
\hline 10 & 3,42 \\
\hline 11 & 2,33 \\
\hline 12 & 2,18 \\
\hline 13 & 2,51 \\
\hline 14 & 2,37 \\
\hline 15 & 2,58 \\
\hline 16 & 2,58 \\
\hline 17 & 3,4 \\
\hline 18 & 3,15 \\
\hline 19 & 2,58 \\
\hline 20 & 2,27 \\
\hline Jumlah & 53 \\
\hline
\end{tabular}

Untuk menentukan hasil dari item ini, maka akan digunakan langkah-langkah sebagai berikut:

1. Menentukan rata-rata : $\frac{\sum \chi}{\text { total_item }}=\frac{56}{20}=\mathbf{2 , 8}$

2. Menentukan kategori : $\frac{\chi}{\text { skor_max }} \times 100 \%=\frac{2,8}{4} \times 100 \%=\mathbf{7 0 \%}$

Dari hasil perhitungan tersebut dapat peneliti simpulkan bahwa prestasi belajar mata pelajaran Sejarah Kebudayaan Islam siswa kelas VII Madrasah Tsanawiyah (MTs) Arruhama Desa Caracas Kecamatan Cilimus Kabupaten Kuningan termasuk dalam kategori baikdengan nilai $65 \%$ karena berada pada interval $61 \%-80 \%$.

\section{Prestasi Belajar Sejarah Kebudayaan Islam}

Siswa Kelas VII MTs Arruhama 


\begin{tabular}{|c|c|c|}
\hline \multirow{2}{*}{ No. } & \multirow{2}{*}{ NAMA } & NILAI \\
\hline & & UTS \\
\hline 1 & Aflah Muzzaka Fitrian Dani & 75 \\
\hline 2 & Ainabila Hasanash Shifati & 30 \\
\hline 3 & Aisyah Zahra Fatimah & 75 \\
\hline 4 & Alya Zalfaa Ayuni & 41 \\
\hline 5 & Andika MahaPutra Hapsandi & 75 \\
\hline 6 & Ane Khoirunnisa & 40 \\
\hline 7 & Bayu Dwi Aditya Saputra & 39 \\
\hline 8 & Dava Anugrah Saputra & 75 \\
\hline 9 & Dea Puspita Sari & 45 \\
\hline 10 & Desi Nurul Ramadhani & 75 \\
\hline 11 & Ekky Ariq Sulthon & 75 \\
\hline 12 & Engga Arya Saputra & 32 \\
\hline 13 & Hilyatul Ulya & 33 \\
\hline 14 & Laura Oktaviani & 75 \\
\hline 15 & Lia NurJanah & 55 \\
\hline 16 & Lita Ernawati & 75 \\
\hline 17 & M. Rifha Rahmatu Sidiq & 33 \\
\hline 18 & Muhammad Dwiky Agustian & 75 \\
\hline 19 & Muhammad Fayyis Khoeri & 35 \\
\hline 20 & Muhammad Tomi Raihan & 31 \\
\hline 21 & Nada Hayatun Nufus & 30 \\
\hline 22 & Nadhifha Zahra S. & 75 \\
\hline 23 & Nazua Nurul Rifani & 31 \\
\hline 24 & Nevanda Hasna Fauziah & 30 \\
\hline 25 & Putri Jasmine Jawas & 75 \\
\hline 26 & Rafi Zaidan Rabbani & 50 \\
\hline 27 & Rezky Agustian & 75 \\
\hline 28 & Ridho Fadhilah & 37 \\
\hline
\end{tabular}




\begin{tabular}{|c|l|c|}
29 & Salmia NurMutia & 75 \\
\hline 30 & Sofia Dewi Lestari Putri & 75 \\
\hline 31 & Thesa Nurshela & 30 \\
\hline 32 & Ummi Nurlaela & 32 \\
\hline 33 & Widhianto Adzani Subhi & 32 \\
\hline \multicolumn{2}{|r|}{ NILAI RATA-RATA } & 1720 \\
\hline
\end{tabular}

Berdasarkan data di atas, maka dapat diketahui nilai rata-ratanya dengan menggunakan rumus ${ }^{24}: \mathrm{Mx}=\frac{\sum X}{N}$

Keterangan :

$$
\begin{array}{ll}
\mathrm{Mx} & =\text { Mean yang kita cari } \\
\sum \mathrm{X} & =\text { Jumlah dari skor-skor (nilai-nilai) yang ada } \\
\mathrm{N} & =\text { Number of cases } \text { (Banyaknya skor-skor itu sendiri) } \\
\mathrm{Mx}=\frac{\sum x}{N} & \\
\mathrm{Mx}=\frac{1720}{33} & \\
\mathrm{Mx}=52.12 &
\end{array}
$$

Berdasarkan perhitungan di atas dapat disimpulkan bahwa prestasi belajar mata pelajaran Sejarah Kebudayaan Islam Siswa Kelas VII MTs Arruhama Kecamatan Cilimus Kabupaten Kuningan dalam kategori cukup karena pada interval $41 \%-60 \%$.

$$
\begin{aligned}
& r_{x y}=\frac{\mathrm{N} \Sigma \mathrm{XY}-(\Sigma \mathrm{X})(\Sigma \mathrm{Y})}{\sqrt{\left\{\mathrm{N} \Sigma \mathrm{X}^{2}-(\Sigma \mathrm{X})^{2}\right\}\left\{\mathrm{N} \Sigma \mathrm{Y}^{2}-(\Sigma \mathrm{Y})^{2}\right\}}} \\
& r_{x y}=\frac{33 \times 91667-(1744)(1720)}{\sqrt{\left\{33 \times 92868-(1744)^{2}\right\}\left\{33 \times 103130-(1720)^{2}\right\}}} \\
& r_{x y}=\frac{3.025 .011-2.999 .680}{\sqrt{\{3.064 .644-3.041 .536\}\{3.403 .290-2.958 .400\}}} \\
& r_{x y}=\frac{25331}{\sqrt{\{23108\}\{444890\}}}
\end{aligned}
$$

${ }^{24}$ Anas Sudijono, Pengantar Statistik 80 . 


$$
\begin{aligned}
& r_{x y}=\frac{25331}{\sqrt{\{10280518120\}}} \\
& r_{x y}=\frac{25331}{101392}
\end{aligned}
$$

$$
=0,2498=0,24
$$

Hasil perhitungan di atas, dapat dikemukakan bahwa terdapat korelasi yang positif antara metode bermain peran terhadap prestasi belajar mata pelajaran Sejarah Kebudayaan Islam (SKI) dengan jumlah $0,24 \%$ sedangkan sisanya 99,76\% dipengaruhi faktor lain, seperti lingkungan, teman, masyarakat dan lainnya.

Kemudian dilakukan perhitungan koefisien determinasi untuk mengetahui seberapa besar kontribusi atau pengaruh variabel $\mathrm{X}$ terhadap variabel $\mathrm{Y}$, dengan rumus sebagai berikut:

$$
\begin{aligned}
& \mathrm{KD}=\mathrm{r}^{2} \times 100 \% \\
& \mathrm{KD}=0,24^{2} \times 100 \% \\
& \mathrm{KD}=0,0576 \times 100 \% \\
& \mathrm{KD}=5,76 \%
\end{aligned}
$$

Jadi prestasi belajar siswa di MTs Arruhama Kecamatan Cilimus Kabupaten Kuningan dipengaruhi oleh metode bermain peran sebesar $5,76 \%$ dan 94,24 dipengaruhi oleh faktor lain.

\section{F. Kesimpulan}

1. Tanggapan responden tentang pengaruh penerapan metode bermain peran terhadap mata pelajaran Sejarah Kebudayaan Islam sudah cukup. Hal ini terbukti dari hasil rata-rata pencapian pengaruh metode bermain peran yang sebagian besar berada pada kategori baik dengan rata-rata prosentase pencapaian sebesar, nilai $70 \%$ karena berada pada interval $61 \%$ $-80 \%$.

2. Prestasi belajar siswa kelas VII dalam pembelajaran Sejarah Kebudayaan Islam di Madrasah Tsanawiyah (MTs) Arruhama Desa Caracas Kecamatan Cilimus Kabupaten Kuningan sudah cukup. Hal ini terbukti dari hasil ratarata pencapaian prestasi belajar siswa sebagian besar berada pada kategori cukup dengan nilai rata-rata prosentase pencapaian sebesar $52,12 \%$ karena berada pada rentang $41 \%$ - 60\%. Dengan perhitungan ini penulis menyatakan adanya perubahan yang cukup dalam segi nilai UTS di MTs Arruhama Kecamatan Cilimus Kabupaten Kuningan.

3. Terdapat pengaruh yang positif antara pengaruh metode bermain peran dengan prestasi belajar siswa pada mata pelajaran Sejarah Kebudayaan Islam kelas VII di Madrasah Tsanawiyah (MTs) Arruhama Desa Caracas Kecamatan Cilimus Kabupaten Kuningan dikategorikan lemah atau rendah dengan $r_{x y}$ sebesar 0, 24 ternyata terletak pada interval 0,20-0,40. Berdasarkan kriteria tersebut maka makna koefisien korelasi termasuk kedalam kategori korelasi yang lemah atau rendah. 


\section{DAFTAR PUSTAKA}

Ahmadi, Abu \& Joko Tri Prasetya. 1997. Strategi Belajar Mengajar (SBM). Bandung: Cv. Pustaka Setia.

Afni, Guza. 2008. Undang-undang Sisdiknas. No.20 Tahun 2003 dan Undangundang Guru dan Dosen No 14 Tahun 2005. Jakarta:Asa Mandiri.

Arikunto, Suharsimi. 1990. Manajemen Penelitian. Jakarta: Rineka Cipta. 1996. Prosedur Penelitian. Jakarta: Rineka Cipta. . 1999. Dasar-Dasar Evaluasi Pendidikan (Edisi Revisi). Jakarta: Bumi Aksara.

B.Uno, Hamzah. 2014. Model Pembelajaran (Menciptakan Proses BelajarMengajar yang Kreatif dan Efektif). Jakarta: PT. Bumi Aksara.

Bahreisy, Salim dan Said Bahreisy. 2006. Terjemah Singkat Tafsir Ibnu Katsir Jilid 6. Surabaya: PT. Bina Ilmu.

Depdikbud. 1996. Kamus Besar Bahasa Indonesia. Jakarta: Balai Pustaka.

Hamdayama, Jumanta. 2014. Model dan Metode Pembelajaran Kreatif dan Berkarakter. Jakarta: Ghalia Indonesia.

Usman, Basyiruddin. 2002. Metodologi Pembelajaran Agama Islam. Jakarta: Ciputat Press.

Mulyono. 2012. Strategi Pembelajaran. Malang: UIN-Maliki Press.

Riduwan. 2013. Dasar-dasar Statistika. Bandung: Alfabeta.

Rusman. 2015. Pembelajaran Tematik Terpadu (Teori, Praktik dan Penilaian). Jakarta: PT. RajaGrafindo Persada.

Subana, dkk. 2000. Statistik Pendidikan.Bandung: Putra Setia.

Sudijino, Anas. 2011. Pengantar Statistik Pendidikan. Jakarta: PT Raja GrafindoPersada.

Sugiyono. 2009. Metode Penelitian Pendidikan. Bandung: Alfabeta.

2011. Metode Penelitian Pendidikan. Bandung: Alfabeta.

Tafsir, Ahmad. 2012. Ilmu Pendidikan Islam. Bandung: PT Remaja Offset.

Tilaar, H.A.R. 2015. Pedagogik Teoritis. Jakarta: PT. Kompas Nusantara. 